\title{
Corrigendum: The effectiveness of the South African Triage Tool use in Mahalapye District Hospital - Emergency Department, Botswana
}

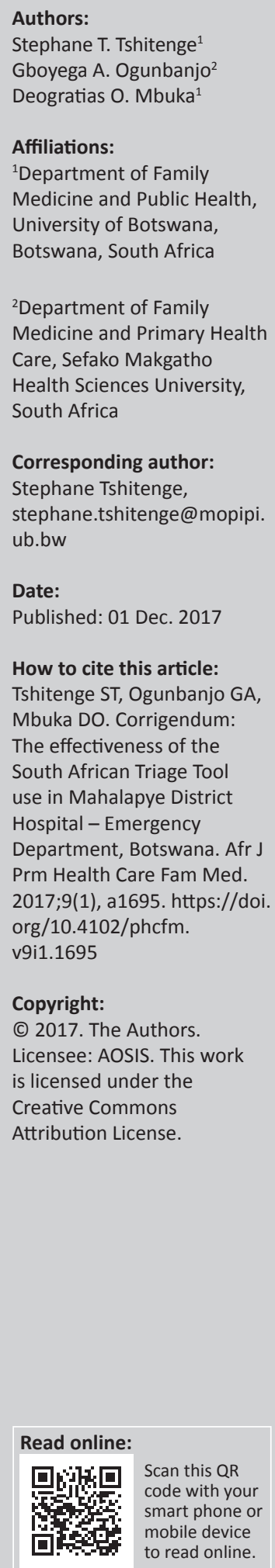

In the title of this article initially published, the spelling of 'Traige Tool' was unintentionally misprinted as 'Triage Toll'. The authors sincerely regret this error. The title should be corrected as follows: The effectiveness of the South African Triage Tool use in Mahalapye District Hospital Emergency Department, Botswana. 